\title{
Teletrabalho: subjugação e construção de subjetividades*
}

\author{
Isabel de Sá Affonso da Costa**
}

S UMÁRIO: 1. Introdução; 2 . Controle na organização contemporânea: formatando subjetividades; 3 . O posicionamento em relação aos discursos; 4. O caminho escolhido: análise das práticas discursivas; 5 . A pesquisa; 6 . 0 grupo de entrevistados; 7. Análise das entrevistas; 8. Comentários finais.

S UMMARY : 1 . Introduction; 2 . Control in the contemporary organization: formatting subjectivities; 3 . The position relative to the discourse; 4 . The chosen path: analysis of the discoursive practices; 5 . The research; 6 . The interviewees; 7. Interview analysis; 8. Final remarks.

Palavras-chave: teletrabalho; poder/saber; subjetividade; discurso; práticas discursivas.

KEY WORD S: telecommuting; power/knowledge; subjectivity; discourse; discursive practices.

Este artigo apresenta resultados de pesquisa de tese que buscou contribuir para o entendimento do teletrabalho, abordando-o da perspectiva teórica do poder/ saber. Trata-se de entender o teletrabalho como discurso que subjuga os indivíduos, mas que, ao mesmo tempo, constrói novos sujeitos e subjetividades. A pesquisa investigou esse processo de assujeitamento, explorando como os teletrabalhadores fazem sentido da experiência do teletrabalho, pela análise de suas práticas discursivas. Para isso, foram realizadas entrevistas abertas com 25 teletrabalhadores em arranjo de home office, residentes na cidade do Rio de Janeiro. Todos os entrevistados mantêm vínculo empregatício com as empresas para as quais teletrabalham e desenvolvem tarefas que podem ser caracterizadas como intensivas em conhecimento.

\footnotetext{
* Artigo recebido em mar. e aceito em ago. 2006. Uma versão preliminar deste trabalho foi apresentada e publicada nos anais do Enanpad 2004.

$*$ Doutora em administração pela Ebape/FGV. Endereço: Av. Presidente Vargas, 642, $22^{\circ}$ andar

— Centro — CEP 20071-001, Rio de Janeiro, RJ, Brasil. E-mail: isabeldesa@uol.com.br.
} 
Telecommuting: subjugating and building subjectivities

This paper article presents the research results of a thesis that aimed at understanding telecommuting from the power/knowledge theoretical perspective. In this sense, telecommuting is understood as a discourse that simultaneously subjugates and builds subjectivities. The article explores how telecommuters make sense out of their experience through the analysis of their discoursive practices. Twenty-five telecommuters residing in the city of Rio de Janeiro, Brazil, were interviewed. All of them hold steady job positions and perform knowledge-intensive tasks.

\section{Introdução}

O teletrabalho constitui tema relativamente recente, tanto como prática quanto na literatura administrativa, especialmente no Brasil. Surgiu como proposta nos anos 1970, como possível resposta à crise do petróleo, ao aumento dos problemas do trânsito nas grandes metrópoles e, ainda, no cenário de maior afluxo das mulheres ao mercado de trabalho. No entanto, é a partir dos anos 1990 que o tema ganha força, especialmente nos países do chamado Primeiro Mundo, em virtude das crescentes sofisticação e massificação das tecnologias de informática e telecomunicações (TICs).

Naturalmente, o trabalho em casa ou fora do escritório não é novidade. No entanto, as formas tradicionais de trabalho a distância diferenciam-se bastante do fenômeno a que assistimos hoje nas organizações. O teletrabalho, viabilizado pelas TICs que permitem a virtualização do espaço e do tempo, não é apenas nova forma de organizar o trabalho. Ele transforma o trabalho de "um lugar para ir" em uma atividade que pode ser feita a qualquer hora e em qualquer lugar. Mais do que isso, ele impacta o próprio significado de organização. Se os indivíduos podem trabalhar em qualquer lugar e a qualquer momento, não é mais tão fácil demarcar as organizações no espaço e no tempo: elas esticam suas fronteiras no espaço porque os teletrabalhadores podem estar em qualquer lugar; elas se esticam no tempo, porque o trabalho não está mais restrito aos horários convencionais do escritório (Brocklehurst, 2001). A organização pode funcionar 24 horas por dia, sete dias por semana, com teletrabalhadores online de qualquer lugar do planeta.

O teletrabalho pode ser entendido, então, como ferramenta e produto da reestruturação global do capital, do trabalho e dos mercados, em direção à fluidez da acumulação flexível. Para entendermos criticamente o teletrabalho dentro desse cenário que reconfigura as práticas e discursos organizacionais, é preciso fugir das abordagens típicas da literatura gerencial sobre o tema. É preciso fugir do determinismo tecnológico que transparece nos tex- 
tos sobre o assunto e propor abordagens teóricas que iluminem que "o teletrabalho pode não ser tanto um capítulo na história da tecnologia, quanto um capítulo na história das ideologias e estratégias gerenciais visando o controle e o uso eficiente do trabalho" (Gerstel, 2000:117, tradução da autora).

Como reconhecem diversos autores (Alvesson e Willmott, 2002; Willmott, 1993; Du Gay et al., 1996; Fournier, 1999; Townley, 1998) no contexto da acumulação flexível a subjetividade "autônoma" do indivíduo produtivo tornou-se recurso econômico fundamental. A subjetividade torna-se, então, ponto crítico para as estratégias de controle organizacional: paralelamente a todas as iniciativas de gerenciamento soft, a toda a estetização e emocionalização do trabalho que caracterizam os discursos/práticas gerenciais da acumulação flexível, todo um aparato é construído visando formatar as subjetividades, e tendo como fim a fabricação dos indivíduos "certos" para o desempenho dos papéis organizacionais. Entre esses discursos floresce o do teletrabalho.

Este artigo apresenta resultados de pesquisa de tese que buscou contribuir para o entendimento do teletrabalho abordando-o da perspectiva teórica do poder/saber. Isso é dizer que o teletrabalho é aqui entendido como discurso que subjuga os indivíduos, mas que, ao mesmo tempo, constrói novos sujeitos e subjetividades. A pesquisa buscou investigar esse processo de assujeitamento, explorando como, com suas práticas discursivas, os teletrabalhadores fazem sentido da experiência do teletrabalho. A preocupação e o foco de análise não são os aspectos gerenciais do teletrabalho, nem as vantagens ou desvantagens da adoção do teletrabalho como decisão estratégica para as organizações, mas que possibilidades de constituição de si (para os teletrabalhadores) o discurso/ prática do teletrabalho promove.

O esforço de investigar que possibilidades de constituição de si se abrem aos indivíduos, ao participarem do regime dos discursos/práticas organizacionais, alinha-se às propostas que buscam explorar como, no contexto atual, o controle organizacional é exercido através da fabricação e do gerenciamento da subjetividade (Alvesson e Willmott, 2002; Du Gay et al., 1996; Fournier, 1999; Willmott, 1993; Townley, 1998).

Essa ligação, que pode ser explorada pela abordagem do poder/saber (Foucault, 1997, 1999a, 1999b), trabalha em registro duplo: por um lado a constituição dos teletrabalhadores como sujeitos (subjetivação), por outro a sujeição dos mesmos aos discursos organizacionais (subjugação), e a conseqüente facilitação do controle organizacional.

\section{Controle na organização contemporânea: formatando subjetividades}

Na perspectiva teórica do poder/saber, o poder não é um privilégio, algo que se possui, que pode ser adquirido, transferido ou delegado. O poder deve ser 
entendido como uma rede de relações, de mecanismos e dispositivos de que todos participam. O poder é algo que "se exerce a partir de inúmeros pontos e em meio a relações desiguais e móveis" (Foucault, 2001:90).

Em vez de agir proibitivamente, o poder opera produtivamente, e uma de suas principais forças é a promoção da subjetividade. O poder, pela produção de discursos que os indivíduos internalizam e que moldam suas disposições psíquicas, cria sujeitos e subjetividades. Ou seja, tornar-se um sujeito significa também tornar-se sujeito a (assujeitar-se) discursos do poder/saber. Como resume Chan (2000:1069, tradução da autora), o processo de "assujeitamento (l'assujetissement) envolve tornar a subjetividade não só amena ao que se possa fazer aos sujeitos (subjugação), como fazê-los dispostos a fazer coisas a si mesmos (subjetivação)".

Como a racionalidade fundamental do poder é governar por meio da liberdade e não da coerção, o poder atua visando constituir indivíduos com a responsabilidade e o interesse por conduzir suas vidas de maneira apropriada. $\mathrm{O}$ poder envolve, então, um conjunto de técnicas e práticas pelas quais os governados são constituídos como sujeitos autônomos e encorajados a exercer sua liberdade de maneira adequada.

O poder apresenta-se, então, como um domínio de relações estratégicas atravessado por discursos vários e conflitantes que lutam pelos corações e mentes. Nesse campo, as organizações surgem como portadoras de conhecimentos sociais e técnicos que produzem e reproduzem modelos particulares de relacionamento social, recursos que os diversos atores organizacionais disputam (Reed, 1999). Essa leitura convida ao entendimento das organizações como práticas sociais estratégicas institucionalizadas ou, como elaboram Cooper e Burrell (1988:105, tradução da autora), "as organizações são máquinas sociais que produzem discursos elaborados de informação/conhecimento, nas quais os sujeitos humanos são uma parte necessária do fluxo material sobre os quais os discursos se inscrevem".

Assim, os discursos e práticas organizacionais correspondentes agem micropoliticamente, para transformar as identidades e o sentido do trabalho. Essa transformação visa fabricar os indivíduos com as atitudes e predisposições necessárias para desempenhar os papéis exigidos pela organização.

Mais especificamente, a governança da organização contemporânea se articula sobre o discurso da "empresa" (Du Gay, Salaman e Rees, 1996). Ele é construído sobre um conjunto de características tais como iniciativa, autoconfiança e a habilidade de aceitar responsabilidade por si e por seus próprios atos. O que define a governança empresarial é a generalização da "forma empresarial" a todas as formas de conduta: da organização e dos próprios indivíduos. Enquanto os antigos departamentos se transformam em unidades de 
negócio, responsáveis por seus próprios resultados, os indivíduos precisam adotar a postura de "empreendedores de si". Essa postura não se limita, na verdade, ao comportamento adequado dentro do ambiente organizacional. Trata-se da formatação de um novo sujeito. A idéia é que a própria vida do indivíduo seja vista como um empreendimento de si - algo que transcende o vínculo circunstancial com a organização para a qual o indivíduo trabalha.

Assim, os discursos típicos da gestão contemporânea, como o do "profissionalismo" (Fournier, 1999) e o da "competência" e do "empreendedorismo de si" (Du Gay, Salaman e Rees, 1996) são articulados em termos que alinham a conduta profissional e a competência ao desenvolvimento pessoal: ser profissional e competente é definido em termos de adotar uma certa relação consigo mesmo, uma postura diante da vida.

Naturalmente, o intento colonizador dos discursos gerenciais não está fadado ao sucesso. Em primeiro lugar, os indivíduos não podem ser reduzidos a meros consumidores passivos das subjetividades arquitetadas pelos discursos gerenciais; em segundo, a organização não é, necessariamente, a fonte de identificação mais importante para os indivíduos.

Mais do que isso, cabe ressaltar que os discursos gerenciais nem sempre produzem o tipo de subjetividade ou a conduta profissional que sua retórica articula, justamente porque os sentidos são construções abertas e altamente contestadas. O processo de construção de sentidos se apresenta como um campo em que diversos discursos, muitas vezes contraditórios, lutam por supremacia - e nessa luta se entrechocam e se combinam. Em suma, os discursos articulam enunciados e práticas, mas não podem ditar sua própria interpretação; interpretações são sempre possibilidades (Holmer-Nadesan, 1996).

São justamente a impossibilidade de fechamento e exaustão dos sentidos e a conseqüente impossibilidade de se determinar identidades estáveis que marcam o espaço possível para a contingência e para a escolha. É o caráter aberto, indeterminado, o deslizamento inevitável na construção de sentidos que abre as possibilidades de invenção, de autonomia, de recriação. Ou seja, as possibilidades de resistência se abrem sobre as maneiras como os indivíduos articulam discursos (sociais, culturais, organizacionais) e fazem sentido de suas experiências.

\section{O posicionamento em relação aos discursos}

Pode-se destacar, esquematicamente, três maneiras de os indivíduos se posicionarem em relação aos discursos: identificação, contra-identificação e desidentificação (Holmer-Nadesan, 1996). 
A identificação acontece quando o indivíduo aceita as identidades providas pelos discursos dominantes, definindo a si mesmo e as suas relações com os outros em termos das posições de sujeito providas por esses discursos. No contexto organizacional, a identificação relaciona-se ao grau em que o indivíduo adota as posições de sujeito providas pelas definições e avaliações que emanam dos discursos gerenciais adotados na organização. A identificação leva à negação das contradições presentes nesses discursos e, ao mesmo tempo, está implícito que os indivíduos negam a possibilidade de conflito entre as posições de sujeito definidas pelos discursos organizacionais e aquelas advindas de outros discursos sociais.

A contra-identificação, por seu turno, opera pela negação das designações formais do indivíduo na organização. No entanto, essa negação revela-se como uma forma de cumplicidade, pois o discurso dominante é experimentado como privação, falta ou insuficiência, mas os indivíduos não se identificam fortemente com posições de sujeito providas por discursos alternativos.

No contexto organizacional, a contra-identificação é marcada pela grande sensibilidade às contradições e antagonismos que ameaçam a coerência dos discursos gerenciais. A contra-identificação leva ao reconhecimento dos interesses subjacentes aos discursos gerenciais e esses interesses são vistos como indo contra, ou ameaçando, os interesses do indivíduo. Essas tensões podem, então, catalisar a rejeição explícita de certas dimensões das posições de sujeito providas pelos discursos organizacionais. No entanto, a resistência não encontra direção, porque nenhuma identidade alternativa subverte abertamente a identidade organizacional.

Já a desidentificação acontece quando os indivíduos desprezam as definições oriundas dos discursos gerenciais e adotam designações provenientes de discursos alternativos. Em outras palavras, as posições de sujeito providas por discursos alternativos, não-gerenciais, moldam as interpretações do indivíduo em relação à organização e ao seu papel dentro dela. A desidentificação não envolve a rejeição dos discursos gerenciais, mas sua substituição por outros como fontes provedoras de posições de sujeito. Na medida em que o conflito entre os diversos discursos permanece não-tematizado, a coexistência pacífica é possível.

Nesse quadro, as possibilidades de resistência referem-se à capacidade dos indivíduos para articular discursos alternativos capazes de subverter as posições privilegiadas nos sistemas dominantes de valores e identidades sociais. No entanto, a interseção poder-subjetividade-resistência não acontece de maneira predeterminada e esquemática. O poder opera tanto pela identificação quanto pela desidentificação e mesmo pela contra-identificação. É preciso então entender como certos efeitos de identificação, desidentificação e contra- 
identificação interagem com outros, alavancando ou limitando possíveis formas de resistência e espaços de autonomia (Fournier, 1999; Holmer-Nadesan, 1996; Willmott, 1993).

Tendo isso em vista, voltamo-nos para o teletrabalho. Que possibilidades de constituição de si o discurso/prática do teletrabalho promove?

Embora o discurso do teletrabalho compartilhe elementos importantes com outros discursos gerenciais correntes, sua prática envolve o elemento peculiar de afastamento físico do local de trabalho. Assim, além de articular uma retórica autodisciplinar de autonomia e liberdade responsáveis, o discurso/prática tenta conciliar situações e sentimentos contraditórios: afastamento físico e vínculo com a organização, proximidade física e indisponibilidade para a família, autonomia com invasão dos espaços íntimos, vida privada e trabalho, transferindo ao responsável e maduro teletrabalhador (e à sua família) o "desafio" (os custos, o estresse) de gerenciar tais paradoxos.

Não obstante, é preciso reconhecer que casa e trabalho são mundos culturalmente diferentes. Trabalho e casa são espaços sociais construídos sobre discursos diferentes, envolvendo pessoas, normas, valores, noções de tempo, práticas e condutas distintas (Tietze, 2002). Como defende DaMatta (1987, 2001), as esferas pessoal e pública - incluindo o trabalho - são espaços de significação diferenciada, com seus códigos, comportamentos e condutas particulares: casa e rua. Os dois mundos, o da casa e o da rua, "são mais que meros espaços geográficos. São modos de ler, explicar e falar do mundo" (DaMatta, 2001:29); tratam-se, ambos, de espaços morais. Misturá-los, então, não é possível sem criar conflitos.

Ao mesmo tempo, ao isolar o teletrabalhador no seu círculo familiar ou de amizades mais íntimas, previamente estabelecidas, que possibilidades de participação e envolvimento social o teletrabalho promove? Ao afastar o teletrabalhador do espaço organizacional, que possibilidades de participação organizacional significativa essa prática incentiva? O que se perde ao se abrir mão do espaço de interação pública que trabalhar representa?

A formação da identidade é um exercício no mundo. É preciso, então, lutar contra o isolamento e as perdas que ele inflige. Isso não quer dizer que os ganhos potenciais do teletrabalho não sejam relevantes e mesmo desejáveis. Precisamos sim de formas mais criativas e flexíveis de trabalho, mas também, e talvez mais, de sujeitos enriquecidos.

Não significa com isso defender a manutenção do trabalho organizacional no centro da vida, nem defender a sociabilidade necessariamente presa às grandes instituições disciplinadoras. Cabe lembrar, também, o potencial das mesmas TICs que viabilizam o teletrabalho no sentido de abrir possibilidades de criação de espaços de interação - ainda que virtuais. Assim, os teletrabalhadores estão, também, postos de frente para um mar de possibilidades de socialização e de ação apenas parcialmente explorado. 


\section{O caminho escolhido: análise das práticas discursivas}

Spink e Medrado (2000), tendo em vista a amplitude da noção de discurso e a necessidade de se trabalhar diferentes níveis de análise, propõem a distinção entre discurso e práticas discursivas. Nessa perspectiva analítica, o discurso remete ao uso institucionalizado da linguagem, institucionalização que pode ocorrer tanto no nível macro dos campos do saber, quanto no nível mais restrito dos grupos sociais. O conceito de discurso remete, então, a uma estrutura de reprodução social e à linguagem entendida a partir das regularidades. É possível, então, estudar determinado fenômeno social referenciando-o às regularidades dos discursos produzidos pelos saberes das ciências sociais.

No entanto, se o objetivo é entender os sentidos que esse fenômeno social - no caso, o teletrabalho - assume na vida dos indivíduos, outra abordagem se faz necessária. É preciso direcionar o foco de análise para a linguagem em uso e para a noção de práticas discursivas. As práticas discursivas são definidas por Spink e Medrado (2000:45) como "linguagem em ação, isto é, as maneiras a partir das quais as pessoas produzem sentidos e se posicionam em relações sociais cotidianas". O conceito remete aos momentos ativos do uso da linguagem, momentos de ressignificações, de rupturas, de reconstrução de sentidos. As práticas discursivas são as diferentes maneiras como as pessoas, com os discursos, ativamente produzem realidades psicológicas e sociais (Pinheiro, 2000).

As práticas discursivas têm como elementos constitutivos: a dinâmica, as formas e os conteúdos. A dinâmica refere-se ao processo dialógico, ao entretecer do diálogo entre os interlocutores. As formas referem-se aos gêneros de fala, os enunciados que orientam a prática cotidiana dos indivíduos. Os conteúdos, por sua vez, são "o conjunto de termos, descrições, lugares-comuns e figuras de linguagem - que demarcam o rol de possibilidades de construções discursivas" (Spink e Medrado, 2000:47). Nas comunicações cotidianas combinam-se repertórios próprios de discursos diversos, revelando a natureza polissêmica das práticas discursivas. É essa polissemia que permite às pessoas o trânsito por contextos variados, bem como a construção de significados a partir dessas experiências.

\section{A pesquisa}

A pesquisa foi realizada por entrevistas abertas. Para a composição do grupo de entrevistados foi usado o critério de acessibilidade. A acessibilidade referiu-se tanto aos casos (pessoas) que se pode atingir com contato pessoal, bem 
como à localização geográfica dos entrevistados. Essa estratégia permitiu chegar-se ao número de 25 entrevistas.

Tendo em vista a característica de dispersão geográfica dos teletrabalhadores, pensou-se de início na realização de pesquisa por telefone ou email. Essa idéia logo foi abandonada; entendeu-se que o caráter exploratório da pesquisa, voltado para entendimento da construção de sentidos, exigia o contato face a face com os entrevistados. Essa escolha levou, por sua vez, à concentração das experiências na cidade do Rio de Janeiro. Em alguns casos, os contatos com os entrevistados aconteceram em mais de uma ocasião, sendo que os contatos posteriores à entrevista se deram por e-mail ou telefone.

Dentro do possível, foi buscada a multiplicidade de experiências com a prática, procurando-se ouvir pessoas que tivessem sido expostas a discursos organizacionais e sociais diversos, bem como a vivências qualitativamente diferentes de teletrabalho. No entanto, é preciso destacar que isso não é o mesmo que buscar uma amostra representativa que permita generalização para grupos sociais amplos (gênero, por exemplo). Assim, qualquer tentativa de generalização dos resultados deve ser feita com cautela, pois o grupo de entrevistados não foi composto visando esse fim.

\section{O grupo de entrevistados}

Como o teletrabalho comporta situações de trabalho diversas e qualitativamente diferentes, o estudo se concentrou nos teletrabalhadores que mantêm vínculo empregatício e estão em regime de home office (escritório em casa) desempenhando tarefas consideradas intensivas em conhecimento. Os teletrabalhadores tiveram, formalmente, seu espaço de escritório transferido para suas casas. As idas à empresa podem ser feitas em bases regulares, para participar de reuniões e encontros ou para utilizar infra-estrutura.

Do grupo de entrevistados, um havia desistido do arranjo de home office poucas semanas antes da entrevista e transferido seu escritório para o espaço de uma ONG, mantendo, no entanto, o vínculo empregatício com sua empresa. Os demais permaneciam em teletrabalho com vínculo empregatício. Os entrevistados trabalham para 10 diferentes empresas, de diversos setores da economia: E1 - petróleo (quatro entrevistados); E2 - rede de televisão (quatro entrevistados); E3 - produtos eletrônicos, informática e consultoria (três entrevistados); E4 - produtos e sistemas de informática (um entrevistado); E5 - produtos e sistemas de informática (um entrevistado); E6 - produtos cirúrgicos, saúde e higiene (oito entrevistados); E7 cartões de crédito (um entrevistado); E8 - rede de fast food (um entrevis- 
tado); E9 - sistemas aeroespaciais e de defesa (um entrevistado); E10 telecomunicações (um entrevistado).

Todas as organizações são multinacionais, à exceção da E2. Os entrevistados atuam em diversas áreas: vendas, consultoria, elaboração de roteiros, desenvolvimento de sistemas, relações corporativas com a comunidade e marketing. Predominam os vendedores: 15. Do grupo, 11 são mulheres e 14 são homens. Nove moram sozinhos (três mulheres e seis homens) e 16 moram com os pais, são casados ou dividem a casa com alguém (oito mulheres e oito homens). Duas das mulheres e cinco dos homens têm filhos morando em casa.

Das organizações, apenas a E3 dá opção de o trabalho ser realizado em casa ou no escritório, ou seja, os três entrevistados da E3 preferem o teletrabalho, mesmo tendo a opção de trabalhar no escritório sempre que quiserem (embora o espaço tenha sido reduzido e o teletrabalho seja incentivado). Nos demais casos, o teletrabalho é uma imposição da empresa - ainda que para alguns represente uma configuração de trabalho interessante. Deve-se destacar que a E1 instituiu o home office para determinadas funções e abre aos seus empregados a possibilidade de se candidatarem a elas.

O tempo de experiência com o teletrabalho, no momento das entrevistas, variava de quatro meses a seis anos. Todos do grupo tiveram experiência com o formato de trabalho tradicional, isto é, escritório, seja na empresa para a qual teletrabalham ou em outra organização.

Os entrevistados constituem um grupo que representa uma elite de trabalhadores. Trabalham para empresas líderes ou altamente competitivas nas suas áreas de atuação; desempenham funções intensivas em conhecimento; dominam o uso de tecnologias diversas; seu nível de escolaridade é alto; são bem pagos; têm boas moradias. São o que se pode chamar de profissionais bem-sucedidos. Sem dúvida, muito de seu reconhecimento social emana de seu sucesso profissional.

Ao mesmo tempo, por serem legítimos representantes dos trabalhadores do conhecimento, os entrevistados constituem o alvo preferencial dos esforços de controle organizacional pela formatação das subjetividades. Não impressiona, então, o fato de suas narrativas estarem carregadas de elementos dos discursos que permeiam as organizações contemporâneas, tais como autonomia, profissionalismo, competência, flexibilidade e individualismo.

\section{Análise das entrevistas}

Em primeiro lugar, chama a atenção o fato de que virtualmente todos os entrevistados se percebem como especiais por estarem conseguindo lidar (bem) com a si- 
tuação de teletrabalho. Quase todos reconhecem que o teletrabalho "não é para qualquer um", pois as dificuldades que a situação traz exigem que se faça uso de uma série de capacidades/qualidades pessoais que, se o indivíduo não possui, precisa desenvolver. Assim, a posição de teletrabalhadores parece reforçar suas identidades de profissionais/indivíduos competentes, autônomos, objetivos, comprometidos, independentes, auto-suficientes, num processo de identificação com as posições de sujeito providas pelos discursos/práticas organizacionais.

\begin{abstract}
Dá uma sensação (...) Eu sinto assim — (...) a Companhia eu não sei — mas você sente isso (...) você como profissional, você, ah! (...) Então, você pega e fala: "caramba, se eu descolar, desligar esse celular um dia" (...) dá a impressão que vai parar tudo! E essa a impressão que dá (...) eu te digo porque você sente, e tudo (...) O referencial é você, então dá essa (...) não é que seja impressão não, eu tenho certeza de que isso está acontecendo. Hoje você é o referencial pra tudo. As coisas passam todas por você. É você quem faz a máquina girar, porque tudo passa por você, você faz as ações e o negócio vai andando. A partir do momento que esse celular parar parece que vai parar tudo!
\end{abstract}

(Teletrabalhador, gerente, E6)

No entanto, ao mesmo tempo em que as identidades de profissionais/indivíduos são reforçadas, torna-se mais difícil articular críticas em relação ao seu papel organizacional ou, dito de outra maneira, há o esforço para acomodar as contradições que a situação do teletrabalho envolve. Por exemplo, embora quase todos os entrevistados reconheçam que passaram a trabalhar até mais do que trabalhavam no escritório ("trabalho 24 horas por dia", "trabalho muito mais do que trabalhava antes" ou "fico ligado no trabalho o tempo todo" são relatos comuns) há o empenho por identificar esse excesso de trabalho com os objetivos pessoais, ou seja, identificar os interesses pessoais com os interesses da organização.

É muito bom pelo lado da flexibilidade, entendeu? É muito bom, porque (...) eu me vejo trabalhando. Quando eu trabalhava na [empresa X], quando eu chegava em casa era impossível ir até a sala e abrir o micro. Eu era contra, eu me sentia tão escravizada com aquele horário que você tinha que cumprir (...). Eu estava me sentindo escravizada com o horário, então quando eu chegava em casa, para mim era um momento que eu estava em casa, não queria saber de ligar máquina e de trabalhar, e hoje eu me vejo (...) eu não vejo problema nenhum hoje de pegar, olhar o meu email (...) às vezes meia-noite estou assistindo um filme, uma coisa assim (...) - Ah! Deixa eu dar uma adiantada naquele e-mail (...) e vou lá, trabalho, faço uma planilha, então hoje não vejo nenhum problema nisso. Eu 
posso trabalhar meia-noite, duas horas da manhã, entendeu, porque eu sei (...) esse meu horário flexível (...) eu sei que às vezes durante o dia eu tirei uma hora pra fazer alguma coisa, ir no médico (...).

(Teletrabalhadora, E5)

O fato de trabalharem muito, então, não ameaça a sua identificação com o discurso/prática organizacional do teletrabalho. Ao contrário, o teletrabalho alimenta-os de posições de sujeito que se articulam àquelas providas pelo discurso do seu empreendedorismo e de seus correlatos: os discursos da empresa e da competência. Assim, os efeitos do discurso/prática do teletrabalho vão além da identificação com o papel organizacional: alimentam suas autonarrativas de vida.

[a] cobrança eu não atribuo exclusivamente à empresa, é uma coisa minha. Ela não pode ser responsável por eu me sentir feliz, me sentir pleno, me sentir satisfeito. Então, é esse tipo de visão que me faz entender que se o meu telefone toca no sábado é porque eu dei liberdade, ou se toca domingo, eu posso querer ou não querer, e aquilo pode trazer ou não trazer resultado para mim. Se não trouxer resultado (...) sou eu quem tem que falar "não me liga sábado" ou eu desligo o celular. Você não é obrigado a estar sob esse tipo de pressão, mas também pode receber ou não receber resultado em cima daquilo. Quer ou não quer? Você tem essa opção, quer fazer venda aos sábados ou não quer? Quer ganhar mais por fazer venda aos sábados ou não quer?

(Teletrabalhador, E1)

Como reflexo da subjetivação via discurso do empreendedorismo de si, percebe-se, de forma geral, que os entrevistados não encaminham a identificação absoluta com seus papéis organizacionais, nem com as empresas para as quais trabalham. Assim, para fazer sentido da experiência do teletrabalho, os entrevistados não articulam elementos dos discursos da lealdade à empresa, nem parecem (à exceção dos roteiristas) dar peso a construir carreiras unicamente em torno das funções que desempenham (vendas, marketing, sistemas etc.). Ao contrário, o que se vê são referências a "estar neste negócio", "estar no mercado" etc.

Por se perceberem profissionais e indivíduos competentes, responsáveis e dedicados, é geral o ressentimento com relação às pessoas "de fora" (tanto as de fora da organização quanto as "do escritório"), os não-teletrabalhadores, que não reconhecem que estar em casa é estar trabalhando. 
você vai trabalhar de forma desesperadora (...) trabalha muito e ninguém tá vendo, ninguém tá vendo. No escritório as pessoas estão vendo que você tá lá, no home office as pessoas não estão te vendo. Às vezes, assim, eu tava adotando uma tática: as pessoas que me ligavam durante o dia pra perguntar, "Aí como é que tá a praia, e aí como é que tá a lagoa" (...) eu ia anotando o nome das pessoas ao longo do dia e eram os últimos e-mails que eu mandava, de madrugada: "E aí o que você tá fazendo agora? Tá dormindo? Eu tô aqui trabalhando... E aí, o que você tá fazendo, tá assistindo novela? Eu tô aqui trabalhando, entendeu"? Todo e-mail meu, o último e-mail, assim $1 \mathrm{~h}$ da manhã 1:30h da manhã era assim.

(Teletrabalhador, E4)

Esse fato, no entanto, não parece ser fator de desidentificação ou de contra-identificação com o discurso/prática do teletrabalho. Ao contrário, o ressentimento se dirige a quem ignora ou não valoriza o teletrabalho e, conseqüentemente, o teletrabalhador; a quem lhe nega o reconhecimento (social) da sua autonomia, independência e empreendedorismo.

Naturalmente, os entrevistados articulam críticas em relação ao teletrabalho, questionando aspectos diversos do discurso/prática, expressando as dificuldades de lidar e fazer sentido da nova situação de trabalho. Mesmo entre aqueles que não enunciam críticas explícitas ou externam desconforto com o teletrabalho, transparece no conteúdo de suas falas que articular a identificação com o discurso/prática é esforço carregado de ambigüidade. Nisso, parece ter papel importante o fato de o teletrabalho expor o teletrabalhador à tensão de conviver constantemente com situações conflitantes: a mistura do espaço da produção e da reprodução, a presença física e a não-disponibilidade para os entes queridos, a tentação do horário flexível e a autopressão por apresentar bons resultados de trabalho. O teletrabalhador é um indivíduo constantemente pressionado pelas posições de sujeito oriundas de discursos conflitantes: exigido, quando "no trabalho" no seu papel de pai/mãe, filho/filha, marido/mulher, irmão/irmã; quando "em casa", exigido no seu papel de trabalhador/trabalhadora.

Da mesma maneira, quando perguntados diretamente sobre a transferência de custos que o teletrabalho pode representar, as reações negativas são, de forma geral, claras, seja pelo gestual, seja pelo conteúdo das falas dos entrevistados. Alguns classificam-na, direta e simplesmente, de "abuso" ou de "desrespeito", enquanto outros elaboram sua crítica tecendo enunciados relativos ao contexto organizacional, social e econômico maior.

(..) as empresas passam essa visão, um pouco daquela coisa: "Olha como somos benevolentes com você, olha como somos legais com você: nós estamos te dando uma chance de você produzir dentro de casa sem ter que se aborrecer na rua". Droga nenhuma, entendeu?! Não há nada de bene- 
volência, eles não estão fazendo nada de bondade, eles estão preocupados com o bolso deles, mais nada! É uma economia brutal, brutal, as pessoas não têm noção: é secretária que você deixa de ter, é trabalho [apoio] de correio que você deixa de ter, é uma economia muito grande! Você vira boy, você vira secretária, você vira tudo, entendeu?

(Teletrabalhadora, E6)

No entanto, em que pese ao conteúdo das críticas ser lúcido e mesmo contundente, existe a tendência à acomodação dessa situação como algo que faz parte do jogo. Seja pelo suposto desrespeito das multinacionais ao Brasil, seja pelo discurso da competitividade, seja pela situação do mercado de trabalho. Essas questões, reais ou alegadas que sejam, enfraquecem as possibilidades de resistência ao discurso/prática do teletrabalho. Como reconhece uma teletrabalhadora, quando questionada sobre a transferência de custos.

\begin{abstract}
a maioria das pessoas [teletrabalhadores] estão em um nível bom, então é um nível que podem muito bem falar: "não, isso não, é meu direito, não são meus direitos". Poderiam (...) mas o que acontece? Quanto maior o nível menor a revolta. Porque as pessoas se (...) conformam com o que elas têm porque elas estão bem. Até injustiças elas suportam, porque isso [a infra-estrutura necessária para a realização do teletrabalho] elas já têm em casa: já têm computador, já têm impressoras, já têm um fax. Então, assim, o que eles estão pedindo (...) você já tem o poder de uso disso. Então, pra você não é nenhuma novidade. Então, por isso, talvez, não dê revolta nessas pessoas e mesmo porque a revolta é típica da pobreza, né?
\end{abstract}

(Teletrabalhadora, E6)

Ou seja, embora exista reconhecimento dos interesses e do ganho que a organização realiza, isso não gera contra-identificação com o discurso/prática. Há, talvez, uma certa desidentificação, mas que, interagindo com os efeitos da identificação, bem como com a percepção da situação do mercado de trabalho, impede a resistência e permite a coexistência pacífica. Talvez isso possa ser devido ao fato de os entrevistados serem trabalhadores de elite e terem seu sucesso social fortemente atrelado ao seu sucesso profissional, como sugere a teletrabalhadora. Ao mesmo tempo, o próprio discurso do empreendedorismo de si torna aceitável que os teletrabalhadores se responsabilizem por todas as tarefas necessárias ao seu trabalho, pois fazer tudo é sinônimo de autonomia; arcar com parte das despesas é contrapartida da independência.

Em suma, a combinação trabalhar demais, ter custos transferidos, ter pouco apoio de infra-estrutura da organização e disponibilizar espaço dentro de casa parecem ser custos acomodáveis, dentro do projeto pessoal de ser um 
profissional/indivíduo bem-sucedido, valorizado, independente, empreendedor. Esse projeto pode ser entendido como uma espécie de joint venture entre o teletrabalhador e a empresa: ambos empreendedores em busca de seus interesses, ambos arcando com os custos do empreendimento.

O projeto só parece ser ameaçado pela pressão da vida familiar e pelo risco que representa o isolamento. Em outras palavras, as fontes potenciais de desidentificação ou mesmo contra-identificação com o discurso/prática do teletrabalho são duas, basicamente: a família e o isolamento do teletrabalhador (da própria organização, do mercado de trabalho e daquilo que alguns deles chamaram "da vida").

Os enunciados adquirem contornos mais dramáticos na questão da família, explicitando o custo de se levar o trabalho para dentro do espaço de convivência familiar. As falas se referem, geralmente, ao custo de disciplinar os familiares a se adaptarem, eles também, à nova realidade, bem como ao desgaste que isso pode representar para o relacionamento familiar.

\begin{abstract}
No início, achei que seria muito melhor. Era visto como uma grande vantagem (...) e toda vez que eu dizia que trabalhava em casa eu tinha uma certa vergonha (...) Assim, era quase como que se eu não fizesse nada, entendeu? As pessoas tinham (...) eu sentia uma certa inveja, (...) um tom irônico: "Ah, trabalha em casa! Que bom, então!" (...) "Que maravilha que você trabalha em casa!” - e eu, realmente, me sentia, assim, uma privilegiada de trabalhar em casa. Hoje, eu não sei (...) não sei se eu sou tão privilegiada de trabalhar em casa. Tem umas coisas muito boas. Por exemplo, eu posso estar com a minha filha, mas eu posso estar em termos porque é uma presença física só, porque a presença, a atenção verdadeira, eu não posso dar. Ao contrário, às vezes acontece o oposto: ela vem falar comigo e eu tenho que dizer "não", "espera", "depois", "agora não posso". Isso cria uma crise com ela, entendeu? Acho que ela se sente meio (...) [como se] o computador [fosse] mais importante do que ela! Essas coisas! E eu me sinto culpada (...).
\end{abstract}

(Teletrabalhadora, E2)

Não causa espanto, então que, de forma geral, sejam os que moram sozinhos ou que não têm filhos morando em casa os que tenham mais facilidade para se adaptar e gostem mais da experiência do teletrabalho. Interessante é a visão geral dos solteiros ou sem filhos em relação à situação familiar $v s$ home office: quase todos avaliam que se tivessem filhos seria muito difícil o teletrabalho. Alguns afirmaram que talvez desistissem do home office ou que tentariam buscar arranjos alternativos: alugar um escritório, manter as crianças ocupadas ou cuidadas fora de casa etc. Essa atitude deixa transparecer 
que, para os entrevistados o mundo da casa e o mundo da rua representam instâncias de vida de naturezas diferentes - conseqüentemente, misturá-las, fundi-las, implica ônus (de vários tipos) para ambas.

Diretamente ligada à questão da família, há a questão da invasão do espaço da casa (da privacidade, da intimidade, do não-trabalho) pelo trabalho. O conteúdo das falas revela o esforço (deles e dos familiares) para tornar esse movimento aceitável, bem como algumas estratégias de acomodação (ocupar as crianças fora de casa, trabalhar de madrugada, até mesmo deixar a casa dos pais e ir morar sozinho). A invasão do espaço da casa se entrelaça também com a questão do excesso de horas trabalhadas e da dificuldade em "desligar" do trabalho. Assim, no que tange a fazer com que os indivíduos trabalhem mais, o teletrabalho poder ser considerado uma iniciativa de sucesso, como ilustra o enunciado abaixo.

Trabalhamos mais horas, isso é o lado ruim. Principalmente com a questão da tecnologia, acho que se a gente simplesmente trabalhasse [em casa], se não tivesse o telefone celular e não tivesse o laptop ou notebook, o que quer que seja, a gente não seria tão escravo do trabalho. Mas não tem jeito, a gente está em casa, mas está 24 horas ligado à empresa. $\mathrm{O}$ nosso celular está ali ligadinho 24 horas, o computador também pode ficar ligado 24 horas, mas aí vai depender de cada um. Se você se deixar levar, você trabalha até 11 horas da noite todos os dias tranqüilamente, porque trabalho existe.

(Teletrabalhador, E1)

Por fim, a invasão do espaço da casa articula-se a um ponto fundamental do teletrabalho, na percepção dos entrevistados: a questão do isolamento do teletrabalhador. Essa sensação de isolamento assume formas e referências diversas nas falas individuais dos entrevistados, mas é presença constante: é sempre enunciado.

O pior é o isolamento, a não-socialização, a perda assim (...) Eu acho que [o pior] é essa mistura de trabalho com a vida, porque a vida não é só trabalho, o trabalho é um aspecto da vida não é? É um aspecto da vida, então quando você traz isso para dentro de casa parece que você mistura tudo. O trabalho está o tempo todo ali na sua casa. Eu acho que é bom você também deixar o trabalho um pouco no espaço do trabalho, no lugar dele, e você estar em casa e curtir outras coisas (...) curtir, você chegar em casa e dar uma desligada, curtir outras coisas. Deixar aquilo para trás, eu acho que é até bom. Eu acho que a base do processo é essa separação.

(Teletrabalhador, E9) 
$\mathrm{O}$ isolamento refere-se também à falta de contato com a própria organização, da interação do dia-a-dia, ao enfraquecimento da sensação de pertencer à organização, à sua "cultura".

Sinto muita falta [da convivência no escritório] (...) a falta dos colegas, até do pós-escritório, você finalizar o escritório, aquele happy hour, de você bater papos com os teus amigos, a gente sente que o ambiente do home office deixa a companhia mais fria, sabe, as pessoas são mais objetivas, te ligam só pra saber a respeito de algumas necessidades (...) é profissional e acabou, entendeu? Sinto muita falta do ambiente de trabalho.

(Teletrabalhador, E6)

A redução do contato com a empresa gera preocupações também com as possibilidades de ascensão profissional. No entanto, o risco de fechamento de possibilidades profissionais é percebido, principalmente, em relação ao mercado de trabalho, e não tanto em relação à empresa. Diversos teletrabalhadores percebem isso claramente e desenvolvem como estratégia de acomodação o contato permanente com amigos de outras organizações: almoços regulares, e-mails, $e$ groups fazem parte desse movimento de evitar o isolamento.

O grande benefício do teletrabalho parece ser o da flexibilidade que permite o bom desempenho do trabalho e, conseqüentemente, o sucesso profissional, a sustentação de suas identidades sociais e a continuidade das narrativas de vida como empreendedores de si. Como resume uma entrevistada,

\begin{abstract}
A flexibilidade é que seduz. Em pleno verão, você não tem nada para fazer, você pode pegar e ir para piscina de oito às dez horas e voltar a trabalhar às dez. Não tem ninguém para controle. Então você agrega uma qualidade de vida, que tem a ver com produção. Se eu entrego o meu projeto num dia, se eu trabalhei de uma hora até as quatro da manhã, se eu fiz em 15 minutos, se eu fiz em 10 horas [isso é comigo].
\end{abstract}

(Teletrabalhadora, E3)

Quando perguntados se deixariam o home office por uma boa proposta de trabalho no modelo tradicional de escritório, os entrevistados afirmaram que sim. A percepção geral é de que a flexibilidade para trabalhar (em termos de horário, de infra-estrutura) são fatores imprescindíveis, mas o teletrabalho em si não é fator de decisão. É, sim, um benefício que deve ser pesado porque permite, até certo ponto, a flexibilidade de gerir o tempo, o dia-a-dia, a carreira, da maneira mais adequada para o indivíduo. No entanto, o teletrabalho não surge como uma experiência capaz de transformar de forma definitiva a vivência do trabalho. 


\section{Comentários finais}

As entrevistas realizadas apontam que, de forma geral, os teletrabalhadores se identificam com o discurso/prática do teletrabalho. A fonte dessa identificação, no entanto, não são as posições de sujeito providas pelo discurso da lealdade à empresa, ou a identificação com os papéis desempenhados dentro das organizações para as quais os entrevistados trabalham. O que transparece é que a fonte dessa identificação é o fato de que o discurso/prática do teletrabalho alimenta as autonarrativas dos teletrabalhadores como empreendedores de si. O empreendedorismo de si é um projeto de encaminhamento da própria vida, que independe mesmo de o indivíduo estar, em determinado momento, empregado ou não. $\mathrm{Ou}$ seja, é um projeto que vai além da identificação com os papéis organizacionais ou com as próprias organizações para as quais os indivíduos trabalham.

A situação de teletrabalho acaba por reforçar a auto-imagem de profissionais/indivíduos responsáveis, comprometidos, independentes e autônomos; para os mais jovens, pode representar, ainda, oportunidade de amadurecimento profissional. Assim, a diminuição da supervisão direta, bem como do apoio/ infra-estrutura da organização, são traduzidas como autonomia, aumento de responsabilidade, oportunidade de mostrar o quanto são, de fato, profissionais competentes.

As críticas enunciadas ao teletrabalho se dirigem, basicamente, ao excesso de horas trabalhadas, à transferência de custos, ao isolamento e à questão da invasão do espaço familiar pelo trabalho. $O$ discurso do empreendedorismo de si é capaz de acomodar as questões do excesso de trabalho e da transferência de custos. O teletrabalho esbarra, no entanto, nos dois outros pontos - isolamento e família - que podem representar fontes potenciais de resistência.

No caso da invasão do espaço da casa pelo trabalho, as fontes de resistência referem-se à dificuldade de equilibrar dois mundos construídos sobre discursos diversos: o da casa e o da rua. Embora os teletrabalhadores que moram com membros da família reconheçam que o tempo com a família aumenta, o tempo para a família não necessariamente o faz. Nesse caso, as estratégias de acomodação são mais limitadas e de difícil implementação, impondo grande custo emocional.

O conteúdo das falas indica que a família (e os papéis desempenhados dentro dela) é fonte significativa de identificação e de potencial resistência ao teletrabalho, especialmente entre os teletrabalhadores cujos filhos moram em casa. Seria necessário aprofundar esse tema, encaminhando pesquisas cujo desenho contemplasse especificamente a questão da situação familiar dos teletrabalhadores, a fim de melhor explorar o sentido que o teletrabalho assume para 
esses teletrabalhadores e suas famílias. Nesse esforço, abordagens teóricas e metodológicas de cunho psicanalítico representariam grande contribuição.

Em virtude da mudança que se opera no vínculo com a empresa - pela redução da presença física, pela falta de supervisão direta e pela flexibilidade de tempo permitida, alguns entrevistados enunciam que o teletrabalho significa novas possibilidades de experimentação profissional. No entanto, isso é articulado com referência a um discurso que, em última instância, sustenta a governança da organização contemporânea: o discurso do empreendedorismo de si. Em suma, o teletrabalho, articulado ao empreendedorismo de si, contribui para reforçar a sensação de independência, de auto-suficiência, de individualismo, de ser capaz de se responsabilizar por suas próprias ações os elementos que baseiam a própria sujeição dos teletrabalhadores à lógica organizacional contemporânea. É esse duplo registro que marca, primordialmente, o assujeitamento do teletrabalhador ao discurso do teletrabalho.

Dessa forma, o espaço que se abre não é preenchido com outras formas de vivência, representando possíveis (novas) fontes de identificação. Talvez isso possa ser um efeito esperado, dadas as características dos entrevistados: quanto mais bem-sucedidos, maiores as compensações e o reconhecimento social advindos do trabalho - e mais difícil substituí-lo como fonte de identificação.

Por fim, cabe notar que as falas dos entrevistados sugerem que, possivelmente, voltar ao espaço do escritório poderia provocar um efeito libertador: liberar o espaço de casa (da privacidade, da intimidade, do descanso), liberar horas trabalhadas, liberar os indivíduos de pensar no trabalho o dia todo.

Deve-se lembrar que a análise aqui tecida refere-se a trabalhadores que podem ser considerados uma elite. Não se deve esperar os mesmos efeitos aqui descritos para teletrabalhadores pouco qualificados, cujas compensações sociais pelo trabalho, bem como as condições de moradia, domínio de tecnologias e acesso a serviços de cuidado para a família sejam mais limitados.

\section{Referências bibliográficas}

ALVESSON, M.; WILLMOTT, H. Identity regulation as organizational control: producing the appropriate individual. Journal of Management Studies, v. 39, n. 5, 2002.

BROCKLEHURST, M. Power, identity and new technology homework: implications for 'new forms' of organizing. Organization Studies, v. 22, n. 3, 2001.

CHAN, A. Redirecting critique in postmodern organization studies: the perspective of Foucault. Organization Studies, v. 21, n. 6, 2000. 
COOPER, R.; BURRELL, G. Modernism, postmodernism and organizational analysis: an introduction. Organization Studies, v. 9, n. 1, 1988.

DAMATTA, R. A casa e a rua: espaço, cidadania, mulher e morte no Brasil. Rio de Janeiro: Guanabara, 1987.

O que faz o brasil, Brasil? Rio de Janeiro: Rocco, 2001.

DUGAY, P.; SALAMAN, G.; REES, B. The conduct of management and the management of conduct: contemporary managerial discourse and the constitution of the 'competent' manager. Journal of Management Studies, v. 33, n. 3, 1996.

FOUCAULT, M. Resumo dos cursos do Collège de France. Rio de Janeiro: Zahar, 1997.

Vigiar e punir. 21. ed. Petrópolis: Vozes, 1999a.

—. Microfísica do poder. 14. ed. Rio de Janeiro: Graal, 1999b.

História da sexualidade I: a vontade de saber. 14. ed. Rio de Janeiro: Graal, 2001.

FOURNIER, V. The appeal to 'professionalism' as a disciplinary mechanism. The Sociological Review, v. 2, n. 47, 1999.

GERSTEL, N. Comments on Gil Gordon's 'Employer scheduling, staffing and work location'. In: Telework and the new workplace of the 21st century. Washington: Department of Labor, 2000. Disponível em: <www.dol.gov/asp/telework/toc.htm>.

HOLMER-NADESAN, M. Organizational identity and space of action. Organization Studies, v. 17, n. 1, 1996.

PINHEIRO, O. Entrevista: uma prática discursiva. In: SPINK, M. J. (Org.). Práticas discursivas e produção de sentidos no cotidiano. São Paulo: Cortez, 2000.

REED, M. Teorização organizacional: um campo historicamente contestado. In: CLEGG, S. et al. Handbook de estudos organizacionais. São Paulo: Atlas, 1999.

SPINK, M. J.; MEDRADO, B. Produção de sentidos no cotidiano: uma abordagem teóricometodológica para análise das práticas discursivas. In: (Org.). Práticas discursivas e produção de sentidos no cotidiano. São Paulo: Cortez, 2000.

TIETZE, S. When "work" comes "home": coping strategies of teleworkers and their families. Journal of Business Ethics, v. 41, n. 4, 2002.

TOWNLEY, B. Beyond good and evil: depth and division in the management of human resources: managing managers in the modern corporation. In: McKINLAY, A.; STARKEY, K. (Eds.). Foucault, management and organization theory. London: Sage, 1998.

WILLMOTT, H. Strength is ignorance; slavery is freedom: managing culture in modern organizations. Journal of Management Studies, v. 30, n. 4, 1993. 